\title{
Fracture behaviour of notched round bars made of PMMA subjected to torsion at $-60^{\circ} \mathrm{C}$
}

\author{
F. Berto ${ }^{a}$, D.A. Cendon ${ }^{\text {b }}$ P. Lazzarin ${ }^{\mathrm{a}, *}$, M. Elices ${ }^{\mathrm{b}}$
}

\begin{abstract}
A B S T R A C T
This paper presents seventy new experimental results from PMMA notched specimens tested under torsion at $-60^{\circ} \mathrm{C}$. The notch root radius ranges from 0.025 to $7.0 \mathrm{~mm}$. At this temperature the non-linear effects previously observed on specimens of the same material tested at room temperature strongly reduce.

The averaged value of the strain energy density over a control volume is used to assess the critical loads to failure. The radius of the control volume and the critical strain energy density are evaluated a priori by using in combination the mode III critical stress intensity factor from cracked-like specimens and the critical stress to failure detected from semicircular notches with a large notch root radius.
\end{abstract}

\section{Introduction}

Modelling damage around notches has proven to be very difficult and strongly dependent on the microstructural aspects of each material. Therefore, proposed fracture criteria are based on critical values of some macroscopic stresses [1], critical virtual cracks [2-5], non-local averaged parameters [6], stress intensity factors [7-12], notch rounding approach [13,14], strain energy density (SED) [15-21], J-integral [22,23] and Cohesive Zone Models [24-29].

Under linear elastic conditions when the stress concentrators are cracks, the stress intensity factors, SIFs, provided by the linear elastic fracture mechanics can be applied. Notch stress intensity factors, NSIFs, substitute SIFs in the case of sharp, zero radius, $\mathrm{V}$-notches. As soon as the notch is blunted, i.e. the notch root radius $R$ is not zero, the stress singularity disappears. The linear elastic fracture mechanics continues to be valid, but up to a some critical value of $R$ which varies from material to material [30]. The problem becomes more involved if the loading symmetry is lost, i.e. when the notched structural component is subjected to mixed mode loading as widely discussed in previous works by other researchers [31-36] and also by the present authors [37-42].

While systematic experimental data on fracture of blunted notched specimens (with notches of different root radii) loaded under mode I and mixed mode loading (I+ II) have been recently provided [33,34,37-41], the results from blunted notched specimens under torsion loading are relatively scarce since the research activity has mainly considered cracked bars under torsion [43-48].

Some results were reported from ceramic notched components under combined tension and torsion, brittle glass and graphite under pure torsion [49-51]. In those papers the authors underlined that no other data were available in the 


\begin{tabular}{|ll|}
\hline Nomenclature \\
$d$ & notch depth \\
$E$ & Young's modulus \\
$E^{\prime}$ & generalised Young's modulus \\
$e_{3}$ & parameter quantifying the influence of the stress state for the calculation of $R_{C}$ \\
$G$ & shear modulus \\
$K_{t, \text { net }}$ & stress concentration factor referred to the net area \\
$K_{\text {IIIc }}$ & mode III critical stress intensity factor from cracked specimens \\
$M_{T}$ & torque applied to the specimen \\
$R$ & notch root radius \\
$r_{0}$ & distance between the notch tip and the origin of the coordinate system for SED computations \\
$r$ & distance between the crack tip and a given point, according to linear elastic fracture mechanics \\
$R_{C}$ & radius of the control volume \\
SED & strain energy density criterion \\
$W_{c}$ & theoretical critical energy density \\
$W$ & average strain energy density \\
$G r e k$ & \\
$2 \alpha$ & notch opening angle \\
$\phi$ & gross diameter of the specimens \\
$\tau_{c}$ & critical stress under torsion loading \\
$\tau_{\text {max }}$ & maximum shear stress calculated on a notched specimen \\
$\tau_{\text {nom,n }}$ & nominal shear stress referred to the net area \\
$v$ & Poisson's ratio \\
\hline
\end{tabular}

literature. In parallel, many researchers have devoted strong efforts to investigate theoretically the stress distributions of sharp and blunt notches under torsion loading and under linear elastic conditions [52-59].

Dealing with the specific case of blunted notches and polymethyl-methacrylate (PMMA) samples, some experimental results under mixed mode (I+ III) loading were provided in [60]. V-notched bars with a constant value of the opening angle $\left(2 \alpha=60^{\circ}\right)$ and a root radius ranging from 0.2 to $1.2 \mathrm{~mm}$ were considered. Some results from semicircular notches with a larger notch root radius $(4.0 \mathrm{~mm})$ were also provided in that contribution. In Ref. [60] cracking and fracture of PMMA shown by the notched specimens loaded in torsion were seen to be very complex. In particular, the torque vs. twist angle curves were characterised by an initial linear-elastic stretch followed by an almost horizontal plateau preceding the final fracture. Strong non-linear effects were observed and documented by those authors.

Similar effects have been recently reported by the present authors who have summarised results for different kind of notched specimens made of PMMA (V-shaped, U-shaped and round shaped notches) [61]. That paper gives an account of about 70 fracture tests from notched specimens (with notches of different depth and radii) under torsion loading. In all tests, maximum loads and failure angles have been measured as a function of notch root radius and specimen geometrical configuration. PMMA specimens under torsion loading behave completely differently from those tested under tensile loading; the notched specimens during the torsion tests display a large plastic behaviour and the influence of the effective resistant net area is found to be the predominant parameter instead of the notch shape details (i.e. notch opening angle and tip radius). A non-conventional approach of these data in terms of strain energy density, as an extension of previous contributions [62-64], has been carried out showing a good agreement between experimental results and theoretical fracture assessment but only when the notch root radius is lower than or equal to $5 \mathrm{~mm}$.

With the aim to strongly reduce (or remove at all) the non-linear effects observed at room temperature, some new tests at low temperature have been performed on the same material.

Altogether 70 new results from PMMA specimens tested under torsion at $-60^{\circ} \mathrm{C}$ are summarised in the present contribution.

The same kind of notches used in [61] have been considered to survey a wide range of stress concentrations. The specimens have been tested at $-60^{\circ} \mathrm{C}$ to have a behaviour closer to the linear elastic one, as previously made under mode I and mode II loadings [37-41].

The results obtained in [61] showed that at room temperature the SED provides a good prediction of the maximum torques up to a limit value of the notch root radius equal to $5 \mathrm{~mm}$. At low temperature, this restriction is removed, with a failure reasonably governed by the stress concentration effects. The averaged SED criterion provides good maximum torque assessments for all specimens, independent of the notch root radius. The control volume radius and the critical SED values were found to be dependent on the temperature. 


\section{Experimental programme}

\subsection{Test samples}

Tests were performed with polymethyl-methacrylate (PMMA), an amorphous glassy polymer tested at $-60^{\circ} \mathrm{C}$.

Different specimen geometries were evaluated, as indicated in Fig. 1; plain specimens (1a) for material characterisation (notch radius at the shoulder $R=40 \mathrm{~mm}$ ), cracked specimens (1b), cylindrical specimens with $U$ - and V-notches (1c and 1d), as well as with semicircular notches (1e), to explore a large range of geometrical configurations.

Specimens were made from $2 \mathrm{~m}$ long round bars of $20 \mathrm{~mm}$ of diameter purchased to a PMMA manufacturer. All these bars were made from the same batch. Bars were cut into $200 \mathrm{~mm}$ long specimens. Notched specimens were machined in a turning lathe: lathe speed was set to 800 r.p.m. and the specimens were cooled by injection of liquid coolant on the machining region to avoid material damage due to an excessive temperature increase. A specific chisel was made for each geometry. These chisels were made of cobalt enriched steel and they all had the shape of its respective notch geometry.

For $U$-notched specimens (Fig. 1c), notches with four different notch root radii, $R$, were tested; $R=0.3,0.5,1.0,2.0 \mathrm{~mm}$. The effect of the net area was achieved by changing the notch depth $d$. Two values of the notch depth were used, $d=2 \mathrm{~mm}$ and $d=5 \mathrm{~mm}$, with a constant gross diameter equal to $20 \mathrm{~mm}$.

For V-notched specimens (Fig. 1d), notches with five different notch root radii, $R$, were tested; $R=0.1,0.3,0.5,1.0$ and $2.0 \mathrm{~mm}$. The notch opening angle was kept constant and equal to $120^{\circ}$. The effect of the net area was achieved by changing the notch depth $d$. Two values were used; $d=2$ and $5 \mathrm{~mm}$ with a constant gross diameter equal to $20 \mathrm{~mm}$.

For semicircular notches (Fig. 1e), notches with seven different notch root radii, $R$, were tested $R=0.5,1.0,2.0,4.0,5.0,6.0$ and $7.0 \mathrm{~mm}$.

All in all, 22 different geometrical configurations were tested. Because each one was repeated at least three times, a total number of about 70 tests were performed. Fig. 2 shows the specimens used in the tests while Table 1 gives the theoretical stress concentration factor $K_{t, \text { net }}$ of all geometries, as determined by FE analyses (ANSYS code, version 11).

The nominal stress has been evaluated according to Coulomb's expression as [65]:

$$
\tau_{\mathrm{nom}, n}=\frac{16 M_{t}}{\pi(\phi-2 d)^{3}}
$$

(a)

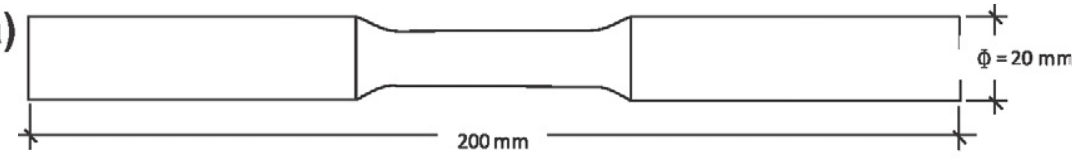

(b)

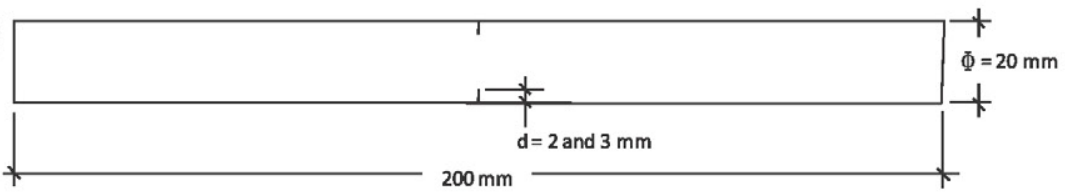

(c)
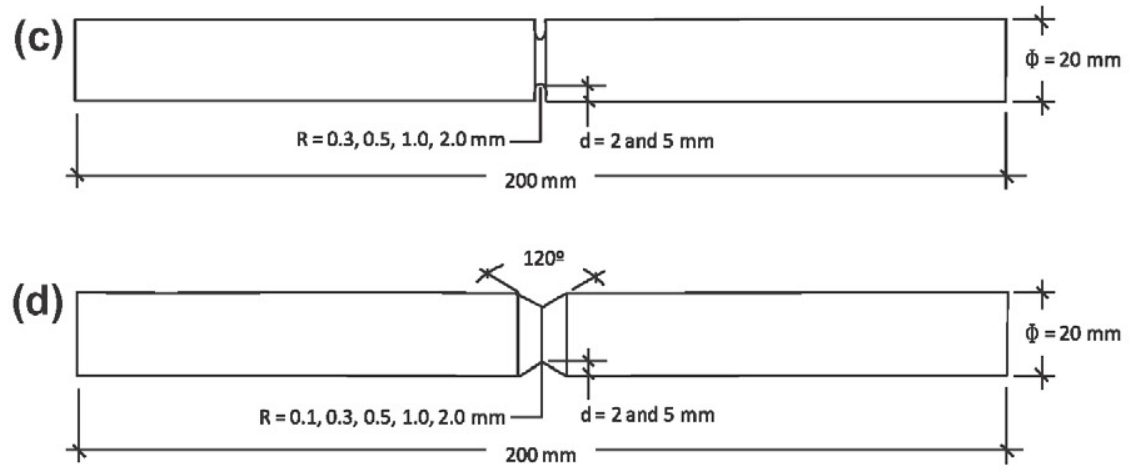

(e)

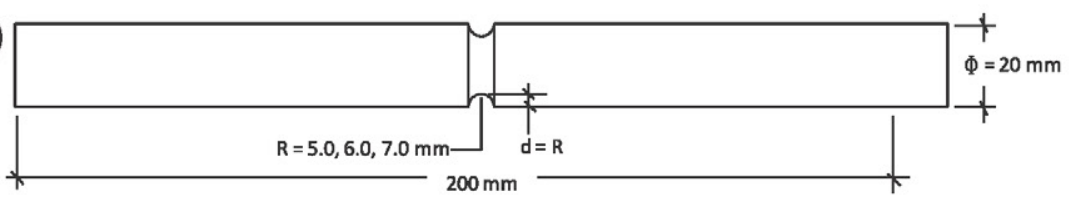

Fig. 1. Geometry of plain, cracked and notched specimens (a-e). 


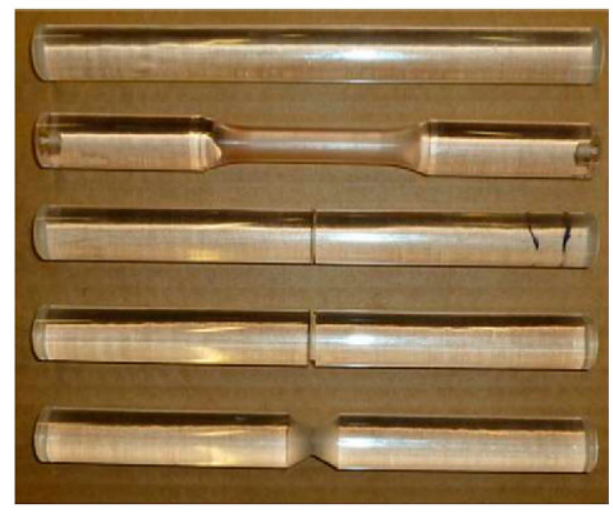

Fig. 2. Photos of the PMMA specimens.

Table 1

Values of the notch stress concentration factor referred to the net area.

\begin{tabular}{|c|c|c|c|}
\hline & $d(\mathrm{~mm})$ & $R(\mathrm{~mm})$ & $K_{t, \text { ne }}$ \\
\hline \multirow[t]{7}{*}{ U-notches } & 5 & 0.3 & 2.30 \\
\hline & & 0.5 & 1.88 \\
\hline & & 1.0 & 1.49 \\
\hline & & 2.0 & 1.21 \\
\hline & 2 & 0.3 & 2.58 \\
\hline & & 0.5 & 2.14 \\
\hline & & 1.0 & 1.75 \\
\hline \multirow[t]{9}{*}{ V-notches } & 5 & 0.1 & 2.54 \\
\hline & & 0.3 & 1.95 \\
\hline & & 0.5 & 1.74 \\
\hline & & 1.0 & 1.50 \\
\hline & & 2.0 & 1.34 \\
\hline & 2 & 0.1 & 2.78 \\
\hline & & 0.3 & 2.13 \\
\hline & & 0.5 & 1.89 \\
\hline & & 1.0 & 1.62 \\
\hline \multirow[t]{7}{*}{ Semicircular notches } & 0.5 & 0.5 & 1.74 \\
\hline & 1 & 1 & 1.59 \\
\hline & 2 & 2 & 1.40 \\
\hline & 4 & 4 & 1.21 \\
\hline & 5 & 5 & 1.14 \\
\hline & 6 & 6 & 1.10 \\
\hline & 7 & 7 & 1.06 \\
\hline
\end{tabular}

where $M_{t}$ is the torque moment applied to the specimen and $\phi-2 d$ the net diameter.

The theoretical stress concentration factor $K_{t, \text { net }}$ which quantifies the severity of the notch geometry can be then evaluated as:

$$
K_{t, \text { net }}=\frac{\tau_{\max }}{\tau_{\text {nom }, n}}
$$

where $\tau_{\max }$ is the maximum stress at the notch tip.

\subsection{Testing procedure}

Low temperature tests have been carried out in a TT-D1115 Instron testing machine.

The angle has been measured by a longitudinal Instron $2620-602$ extensometer of $12.5 \mathrm{~mm}$ of gauge length, $\pm 2.5 \mathrm{~mm}$ and $0.15 \%$ error at full scale (see Fig. 3 ).

Low temperature has been reached by controlled injection of liquid $\mathrm{N}_{2}$ into an Instron environmental chamber. In order to avoid damage on the specimens due to large thermal stress gradients, temperature has been decreased progressively using a constant rate of $-1^{\circ} \mathrm{C} / \mathrm{min}$. Temperature inside the chamber has been controlled by using a Pt-100 thermometer. Additionally a thermocouple has been attached to the specimen in order to check the temperature on its surface. To ensure a 


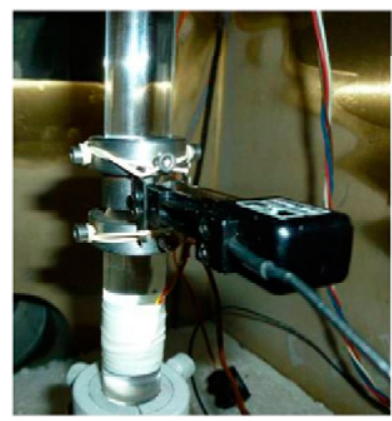

(a)

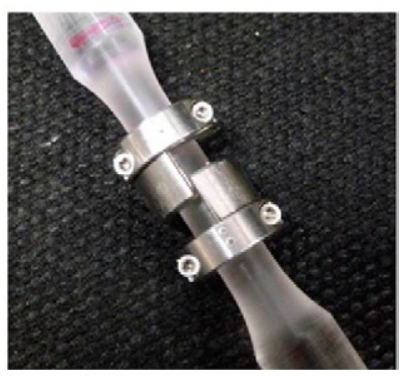

(b)

Fig. 3. Detail of the devices used to measure the rotation angle in (a) notched specimens and (b) 12.5 mm unnotched specimens.

homogeneous temperature distribution inside the specimen, the temperature $-60^{\circ} \mathrm{C}$ has been kept constant for $20 \mathrm{~min}$ before starting each test. All samples were tested up to failure under displacement control at rate of $2^{\circ} / \mathrm{min}$. The test speed was selected after a set up of the system to guarantee that the strain rate does not affect the final results. This angle rate allows a direct comparison with the tests carried out at room temperature.

Fig. 4a shows the environmental chamber during a test and Fig. $4 \mathrm{~b}$ shows a plain specimen at failure.

Sudden brittle or quasi-brittle failures, with fragmentation of small parts of the specimens embracing the highly stressed region, systematically occurred for values of the notch depth lower than $d=2 \mathrm{~mm}$, both for $\mathrm{U}$ - and V-notches, independent of the notch radius, $R$. Again, in the case of semicircular notches, fragmentation occurred when the notch depth (here $d=R$ ) was lower than or equal to $2 \mathrm{~mm}$. The same phenomenon occurred also in the V-notches with $d=5 \mathrm{~mm}$, but only when the notch

(a)

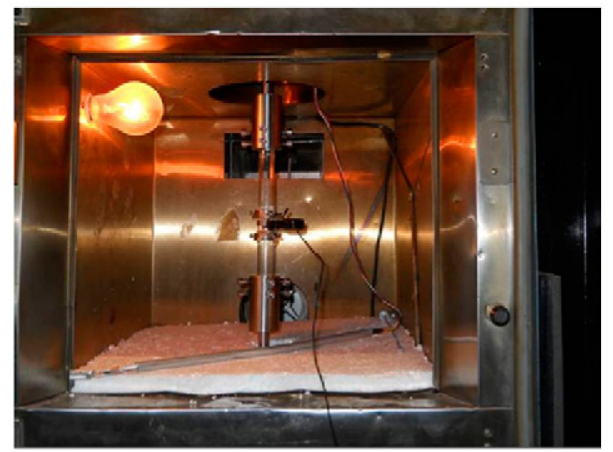

(b)

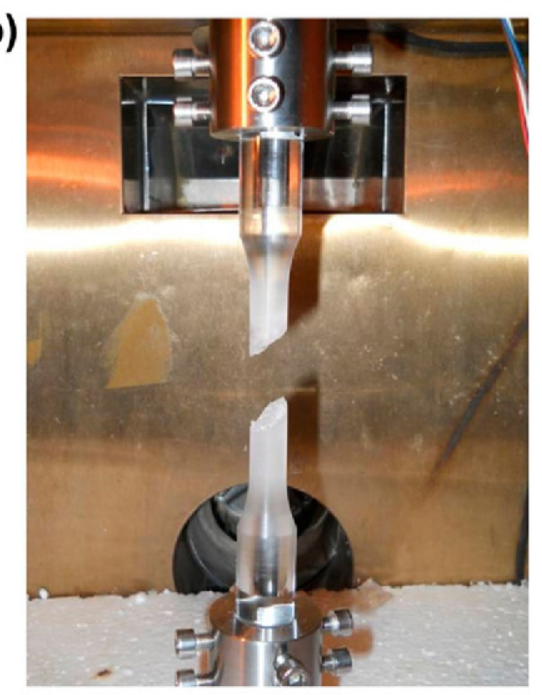

Fig. 4. Instron environmental chamber (a) and example of a unnotched specimen at failure (b). 
radius $R$ was greater than or equal to $1 \mathrm{~mm}$. All samples broke suddenly without evident cracking before the final failure. For the specimens characterised by final fragmentation the fracture surface was irregular with a relevant detachment of material that compromised the original geometrical configuration not only on the notch bisector line but also along the notch flanks.

On the other hand, the topography of the fracture surfaces of the specimens which did not explode at the failure was characterised by irregular inclined fracture planes with partial detachment of the material in the close neighbourhood of the notch tip. For these reasons it was not possible to track precisely the actual crack path at fracture initiation.

The effects of the fragmentation at failure are particularly evident in Fig. 5 whereas they are limited in Fig. 6. The effect is absent in Fig. 7.

\subsection{Experimental results}

In previous works by the authors [28,37-39] tensile tests with PMMA specimens at low temperatures had shown an almost linear elastic mechanical behaviour up to failure (see Fig. 8a). However, in the torsion tests reported here the specimens exhibited a non-linear behaviour from the beginning of the loading process. Fig. 8b shows a typical torque versus angle curve obtained in the characterisation tests. The abovementioned non-linear behaviour can be observed.

Table 2 lists all experimental results from $U$-notched specimens. For every notch geometry, the maximum torque and the nominal shear stress (referred to the net sectional area of the specimens) are reported. Such nominal shear stress has been evaluated according to Eq. (1).

As it can be realised, loads increase as the notch depth decreases, as expected. They are also sensitive to the variation of the notch root radius: by increasing the radius the critical load also increases and this is true especially for the notch depth equal to $5 \mathrm{~mm}$.

Table 3 shows all the experimental results from V-notched specimens. For every combination of geometrical parameters, maximum loads (torque and $\tau_{\text {nom,n }}$ ) were summarised as a function of the chosen notch radii and depths. It is worth noting that for V-notches the load increases while decreasing of notch depths, whereas it is less sensitive to the notch root radius.

By comparing the results from $\mathrm{U}$-and $\mathrm{V}$-notches it is clear that also the influence of the notch opening angle on the maximum torque load is very limited.

Table 4 summarises the results from semicircular notches in terms of maximum torque and nominal shear stresses. In this case, as the notch radius increases, the maximum torque decreases. The reason behind this result lies on the net area reduction with the increase of notch tip radius in the case of semicircular notched specimens.

Table 5 summarises the results from cracked-like specimens (averaged notch root radii equal to $0.025 \mathrm{~mm}$ ) in terms of maximum torque and nominal shear stresses. As widely discussed and proved in Ref. [39] dealing with the same material tested at $-60^{\circ} \mathrm{C}$, a notch radius lower than $0.1 \mathrm{~mm}$ can be assimilated to a sharp notch.

The notch tip radius was found to be $0.025 \pm 0.005 \mathrm{~mm}$. Four different measurements were carried out for each specimens, in order to have a representative value. The sharp notches were obtained by machining an initial crack of $0.075 \mathrm{~mm}$ of depth with a radial saw, and then the cracks were sharpened by using a diamond wire saw until getting the final dimensions of the notch.

Two different crack depths have been considered, $d=2$ and $3 \mathrm{~mm}$. These values will be used in the next section to determine the mode III critical stress intensity factor, $K_{\text {IIIc. }}$.

Torque versus angle ( $25 \mathrm{~mm}$ gauge length) curves obtained at room temperature are plotted in Fig. 9 [61]. Due to the relatively low experimental scatter, only one single curve for each notch geometry is shown. It can be observed how the

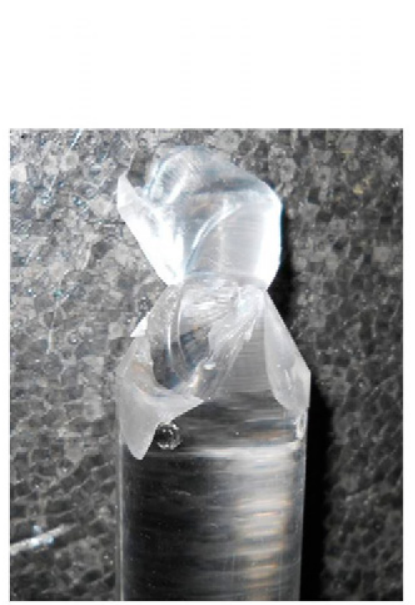

(a)

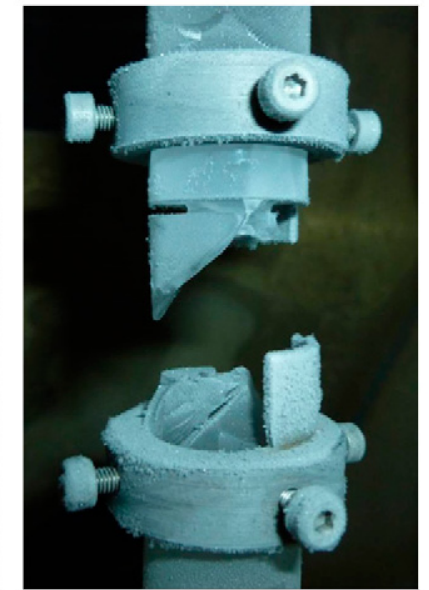

(b)

Fig. 5. Fragmentation occurred during a test on a V-notched (a) and a U-notched (b) specimen ( $d=2 \mathrm{~mm})$. 


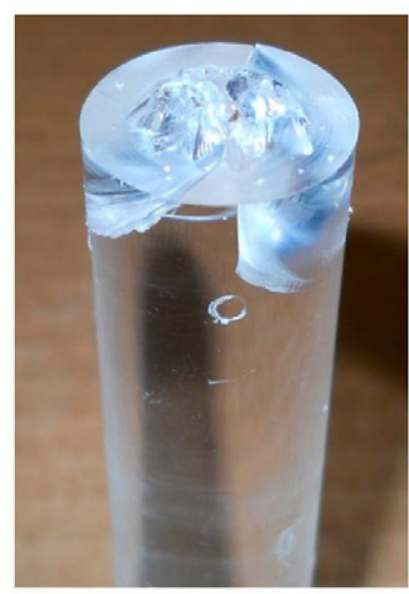

(a)

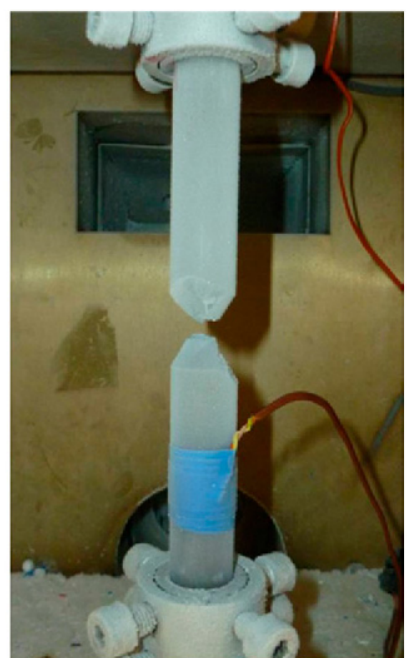

(b)

Fig. 6. Failures with partial fragmentation for (a) a U-notched specimen and (b) a $V$-notched specimen $(d=5 \mathrm{~mm})$.

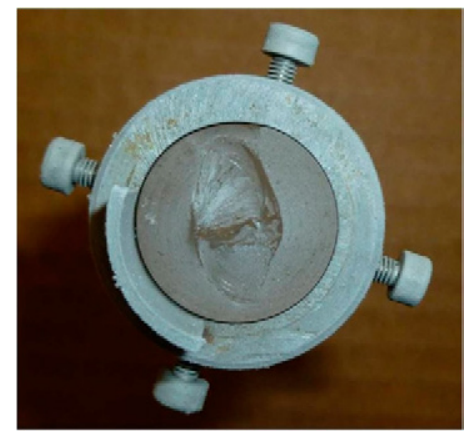

Fig. 7. Failures without fragmentation for a semicircular notch $(R=6 \mathrm{~mm})$.

behaviour is remarkably non-linear. Actually, for $\mathrm{V}$ and $\mathrm{U}$ notched specimens, the maximum load depends only on the notch shape but not on the notch tip radius. This behaviour suggests that a large amount of plasticity/non-linearity is developing on the notched section and therefore all points in this region have a similar stress value, which is governed by the almost constant stress value of the plateau on the material stress-strain curve once plasticity has been fully developed.

Torque versus angle (again with $25 \mathrm{~mm}$ gauge length) curves obtained at $-60^{\circ} \mathrm{C}$ are plotted in Fig. 10 . Once more, for the sake of simplicity and given the repeatability of the results, only one single curve for each geometry is provided.

Previous tests on three point bending tests had shown an almost linear elastic behaviour up to failure [27-29]. Therefore, a similar behaviour was expected on these torsion tests. However, although the temperature decrease makes the specimens behaviour considerably more brittle in terms of failure angles, it can be noticed how the curves show a non-linear shape from their beginning, independently of the type of notch geometry.

However, unlike in the case of the room temperature tests, the maximum torque that each specimen type is able to withstand is dependent on the notch tip radius. In the author's opinion, this result suggests that failure is primarily governed by the stress concentration at the notch tip. Therefore, although the decrease of temperature has not been able to "linearise" the specimens behaviour, it has succeeded in the purpose of concentrating all the damage and failure mechanisms at the notch tip.

\section{Averaged strain energy density}

The averaged strain energy density, SED, criterion, first proposed in [19], states that brittle failure occurs when the mean value of the strain energy density over a control volume, $\bar{W}$, (which becomes an area in two dimensional cases) is equal to a critical energy $W_{c}$. The first to apply a point related energy based approach to V-sharp notches were Sih and Ho [15] (see also references therein). They evaluated the strain energy density in a point at a certain distance from the notch tip. 

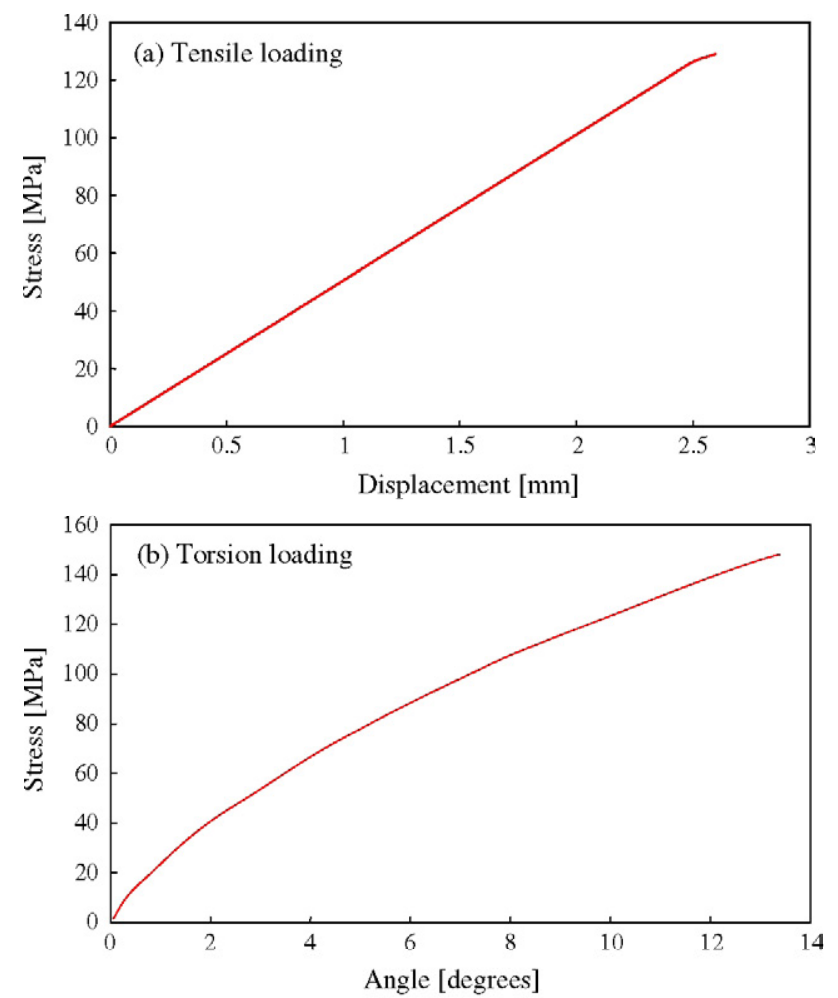

Fig. 8. Unnotched specimens at low temperature (PMMA at $-60^{\circ} \mathrm{C}$ ): tensile loading (a) and torsion loading (b).

Table 2

Maximum torque measured from $\mathrm{U}$ notched specimens and corresponding nominal shear stress evaluated on the net transverse section area.

\begin{tabular}{|c|c|c|c|c|}
\hline$d(\mathrm{~mm})$ & $R(\mathrm{~mm})$ & Torque (Nm) & $\tau_{\text {nom }, n}(\mathrm{MPa})$ & $\operatorname{SED}\left(\mathrm{MJ} / \mathrm{m}^{3}\right)$ \\
\hline \multirow[t]{12}{*}{5} & 0.3 & 17.95 & 91.42 & 3.26 \\
\hline & 0.3 & 22.65 & 115.36 & 5.19 \\
\hline & 0.3 & 19.97 & 101.71 & 4.03 \\
\hline & 0.5 & 26.14 & 133.13 & 6.92 \\
\hline & 0.5 & 27.31 & 139.09 & 7.55 \\
\hline & 0.5 & 27.47 & 139.90 & 7.64 \\
\hline & 1 & 29.31 & 149.27 & 8.09 \\
\hline & 1 & 29.8 & 151.77 & 8.36 \\
\hline & 1 & 30.56 & 155.64 & 8.80 \\
\hline & 2 & 31.36 & 159.72 & 8.36 \\
\hline & 2 & 30.79 & 156.81 & 8.06 \\
\hline & 2 & 32.36 & 164.81 & 8.91 \\
\hline \multirow[t]{9}{*}{2} & 0.3 & 114.79 & 142.73 & 10.34 \\
\hline & 0.3 & 112.21 & 139.52 & 9.58 \\
\hline & 0.3 & 90.89 & 113.01 & 6.29 \\
\hline & 0.5 & 104.15 & 129.50 & 8.21 \\
\hline & 0.5 & 115.15 & 143.18 & 10.04 \\
\hline & 0.5 & 114.94 & 142.92 & 10.01 \\
\hline & 1 & 124.65 & 154.99 & 11.17 \\
\hline & 1 & 76.24 & 94.80 & 4.17 \\
\hline & 1 & 114.69 & 142.61 & 9.45 \\
\hline
\end{tabular}

The SED approach is based both on a precise definition of the control volume and the fact that the critical energy does not depend on the notch sharpness. Such a method was formalised and applied first to sharp (zero radius) V-notches [19] and later extended to blunt $U$ - and V-notches under mode I loading [21]. On a tensile loading case, the radius $R_{C}$ of the control volume over which the energy has to be averaged, depends on the ultimate tensile strength, the fracture toughness and Poisson's ratio in the case of static loads. In the case of sharp V-notches the control volume is simply a circular sector having its centre on the point of stress singularity (Fig. 11). The volume assumes a crescent shape in the case of blunt notches. A precise definition of the control radius under linear elastic hypothesis is given in Ref. [21] for mode I and mixed, I+ II, loading 
Table 3

Maximum torque measured from $\mathrm{V}$ notched specimens and corresponding nominal shear stress evaluated on the net transverse section area.

\begin{tabular}{|c|c|c|c|c|}
\hline$d(\mathrm{~mm})$ & $R(\mathrm{~mm})$ & Torque (Nm) & $\tau_{\text {nom }, n}(\mathrm{MPa})$ & SED $\mathrm{MJ} / \mathrm{m}^{3}$ \\
\hline \multirow[t]{21}{*}{5} & 0.1 & 29.06 & 148.00 & 8.10 \\
\hline & 0.1 & 31.79 & 161.91 & 9.96 \\
\hline & 0.1 & 19.02 & 96.87 & 3.47 \\
\hline & 0.1 & 22.43 & 114.24 & 4.82 \\
\hline & 0.1 & 28.16 & 143.42 & 7.60 \\
\hline & 0.3 & 20.3 & 103.39 & 3.96 \\
\hline & 0.3 & 18.6 & 94.73 & 3.33 \\
\hline & 0.3 & 19.1 & 97.28 & 3.51 \\
\hline & 0.3 & 24.24 & 123.45 & 5.65 \\
\hline & 0.3 & 22.31 & 113.62 & 4.79 \\
\hline & 0.5 & 18.68 & 95.14 & 3.35 \\
\hline & 0.5 & 19.2 & 97.78 & 3.54 \\
\hline & 0.5 & 19.73 & 100.48 & 3.74 \\
\hline & 0.5 & 18.78 & 95.65 & 3.39 \\
\hline & 0.5 & 20.23 & 103.03 & 3.93 \\
\hline & 1 & 31.59 & 160.89 & 9.44 \\
\hline & 1 & 32.64 & 166.23 & 10.08 \\
\hline & 1 & 30.79 & 156.81 & 8.97 \\
\hline & 2 & 31.39 & 159.87 & 8.82 \\
\hline & 2 & 33.7 & 171.63 & 10.16 \\
\hline & 2 & 31.63 & 161.09 & 8.95 \\
\hline \multirow[t]{12}{*}{2} & 0.1 & 93.87 & 116.72 & 6.43 \\
\hline & 0.1 & 122.52 & 152.34 & 10.96 \\
\hline & 0.1 & 98.67 & 122.69 & 7.11 \\
\hline & 0.3 & 94.19 & 117.12 & 6.45 \\
\hline & 0.3 & 79.39 & 98.71 & 4.58 \\
\hline & 0.3 & 78.52 & 97.63 & 4.48 \\
\hline & 0.5 & 73.91 & 91.90 & 3.95 \\
\hline & 0.5 & 77.94 & 96.91 & 4.38 \\
\hline & 0.5 & 80.31 & 99.86 & 4.65 \\
\hline & 1 & 93.45 & 116.20 & 6.11 \\
\hline & 1 & 102.82 & 127.85 & 7.40 \\
\hline & 1 & 124.65 & 154.99 & 10.88 \\
\hline
\end{tabular}

Table 4

Maximum torque measured from semicircular notched specimens and corresponding nominal shear stress evaluated on the net transverse section area.

\begin{tabular}{|c|c|c|c|c|}
\hline$d(\mathrm{~mm})$ & $R(\mathrm{~mm})$ & Torque (Nm) & $\tau_{\text {nom }, n}(\mathrm{MPa})$ & $\operatorname{SED}\left(\mathrm{MJ} / \mathrm{m}^{3}\right)$ \\
\hline 5 & 5 & 30.3 & 154.32 & 6.66 \\
\hline 5 & 5 & 28.22 & 143.72 & 5.78 \\
\hline 5 & 5 & 28.39 & 144.59 & 5.85 \\
\hline 6 & 6 & 15.21 & 151.30 & 5.74 \\
\hline 6 & 6 & 15.53 & 154.53 & 5.23 \\
\hline 6 & 6 & 15.77 & 156.87 & 6.17 \\
\hline 7 & 7 & 7.12 & 167.88 & 6.24 \\
\hline
\end{tabular}

Table 5

Maximum torque measured from cracked specimens and corresponding nominal shear stress evaluated on the net transverse section area.

\begin{tabular}{|c|c|c|c|c|}
\hline$d(\mathrm{~mm})$ & $R(\mathrm{~mm})$ & Torque (Nm) & $\tau_{\text {nom }, n}(\mathrm{MPa})$ & $\operatorname{SED}\left(\mathrm{MJ} / \mathrm{m}^{3}\right)$ \\
\hline 3 & $\leqslant 0.025$ & $\begin{array}{l}57.37 \\
54.53 \\
60.95 \\
64.82\end{array}$ & $\begin{array}{l}106.48 \\
101.21 \\
113.13 \\
120.31\end{array}$ & $\begin{array}{l}5.55 \\
5.02 \\
6.27 \\
7.09\end{array}$ \\
\hline 2 & $\leqslant 0.025$ & $\begin{array}{l}95.62 \\
97.36\end{array}$ & $\begin{array}{l}118.89 \\
121.06\end{array}$ & $\begin{array}{l}7.01 \\
7.26\end{array}$ \\
\hline
\end{tabular}

conditions. The averaged value of the strain energy density (SED) over a well-defined control volume surrounding the notch tip has been used profitably to summarise the static strength data of notched specimens under static loads [19,37-42] as well as notched components and welded joints under fatigue loading. Dealing with static loads, the SED approach has successfully been applied to assess the critical loads to failures of brittle or quasi-brittle materials weakened by $U$ - and Vnotches. About 1200 experimental data under mode I and mixed mode conditions (I + II) were summarised in Refs [40,42]. 

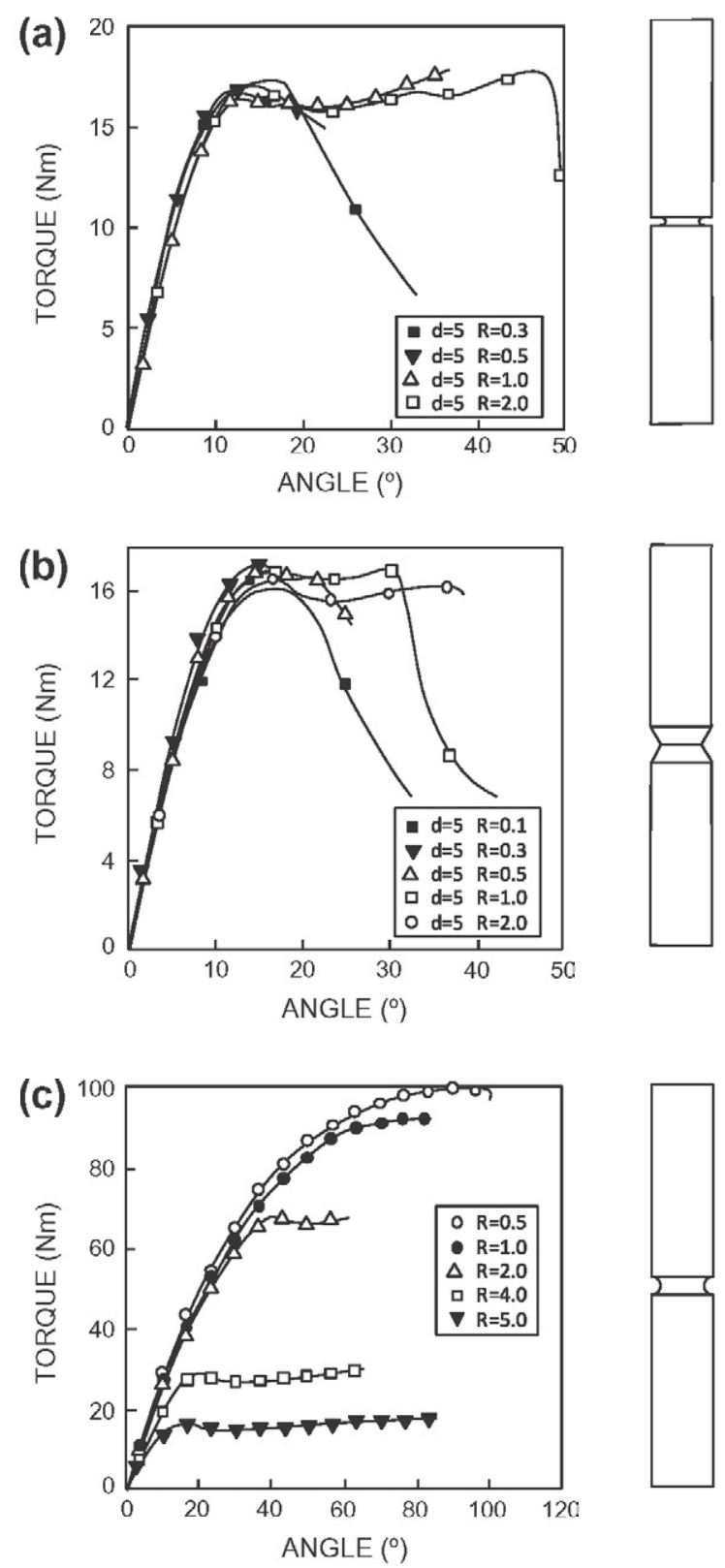

Fig. 9. Experimental results obtained in the room temperature torsion tests for (a) U-notched specimens, (b) V-notched specimens and (c) circular notched specimens.

Recently the SED approach was also applied to summarise a number of fatigue data from V-notched specimens subjected to uniaxial and multiaxial loading $[63,64]$. Under torsion loading a number of non-linear elastic effects were detected resulting in a control volume dependent on the loading mode [61]. The volume radius under torsion resulted to be much greater than the radius under tensile loading.

Before going into details about the specific calculations for the SED criterion, some features should be given about how the SED criterion has been applied to these tests. The SED criterion is applied here assuming linear elastic behaviour, however, as we describe in the last paragraph of Section 2.3, the present tests were characterised by a slight non-linear behaviour. Therefore some assumptions have been made in order to translate our slight non-linear behaviour to an elastic linear one for the evaluation of the parameters required for the definition of the control volume. It is worth mentioning that also Seweryn [7] applied a linear elastic fracture criterion based on the critical value of the notch stress intensity factor although for duraluminum specimens some visible plastic deformations were present. In that paper some important guidelines were given to overcome the non-linearity occurring when testing unnotched or severely notched specimens. 

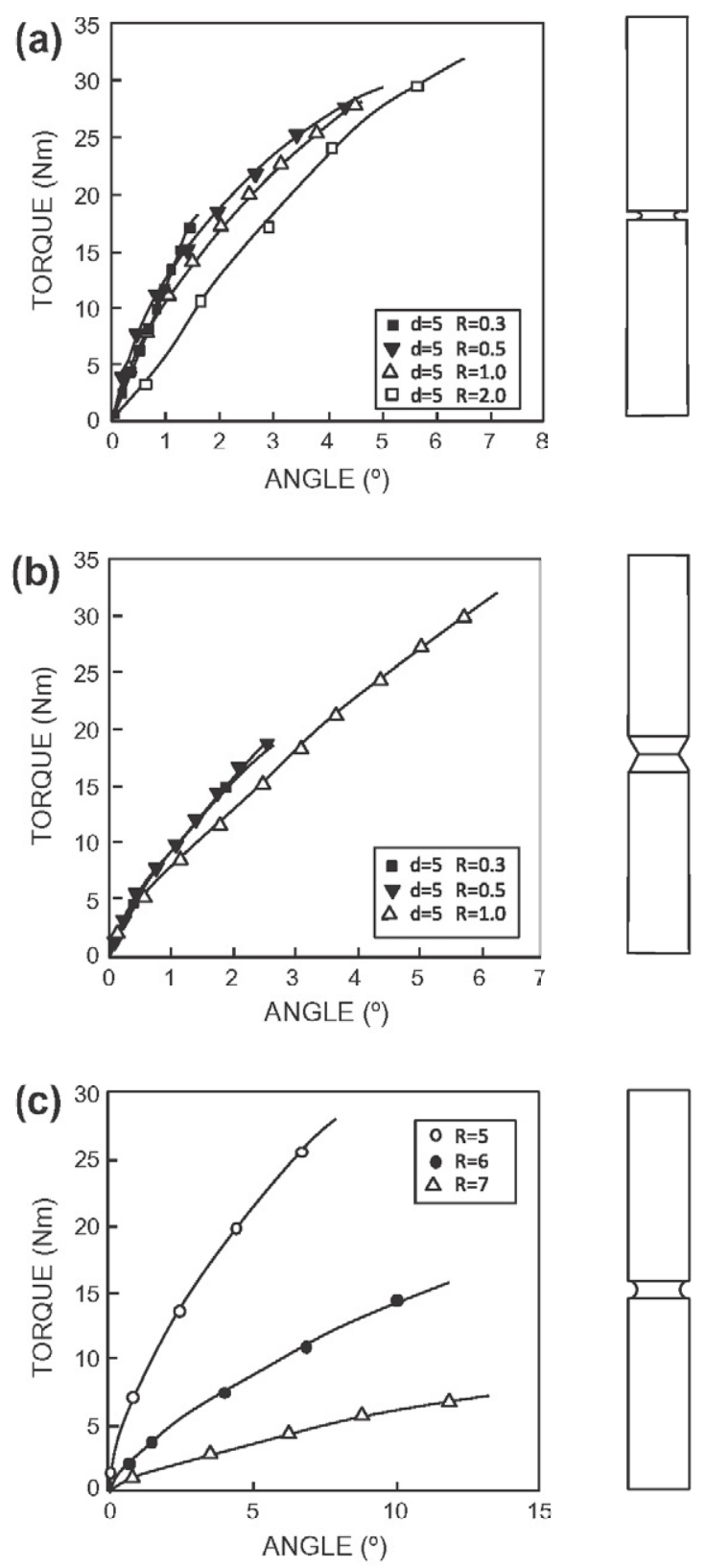

Fig. 10. Experimental results obtained in the low temperature $\left(-60^{\circ} \mathrm{C}\right)$ torsion tests for (a) U-notched specimens, (b) V-notched specimens and (c) circular notched specimens.

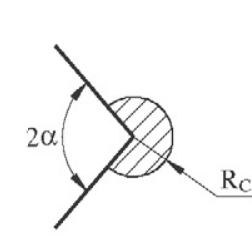

(a)

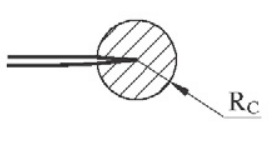

(b)

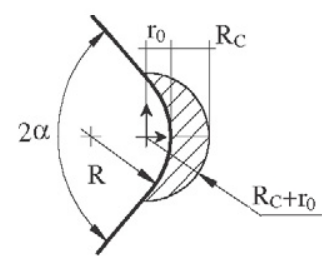

(c)

Fig. 11. Shape of the control volume (area) for V-sharp notches (a), cracks (b) and blunt V-notches (c). The outer radius of the crescent shape volume, $R_{C}+r_{0}$, intersects the semicircular notch root edge or the rectilinear flanks of the V-notch. 
Unnotched specimens often exhibit a non-linear behaviour also under tensile loading whereas the behaviour of notched specimens remains linear as underlined in Ref. [7].

Under these circumstances and extending the same concept to the torsion loading, the critical stress $\tau_{c}$ should be substituted by the maximum stress existing at the edge at the moment preceding the cracking, as underlined in Ref. [7] where it is also recommended to use tensile specimens with large semicircular notches to avoid any notch sensitivity effect. The critical stress $\tau_{c}$ has been estimated here by using the average value of the stresses obtained from semicircular notches with a radius equal or greater than $5 \mathrm{~mm}$ (see Table 4). All these radii are characterised by a very low value of the stress concentration factor which is in all the cases lower than 1.14 (see Table 1).

The critical stress intensity factor has been obtained by using the following equation according to the traditional linear elastic fracture mechanics:

$$
K_{\text {IIIc }}=\lim _{r \rightarrow 0} \sqrt{2 \pi r} \tau_{\theta z}
$$

The results for the considered cases are reported in Table 6. An average value of $6.02 \mathrm{MPa} \mathrm{m}^{0.5}$ has been obtained. To apply Eq. (3) the numerical models of the cracked specimens have been carried out (Ansys 11.0) by using a very fine mesh near the crack tip and the shear stress $\tau_{\theta z}$ has been determined along the bisector line.

Table 7 summarises all the material parameters $\left(\tau_{c}, G, v\right.$ and $\left.K_{\text {lllc }}\right)$ that are going to be used in the coming sections. All the data are compared with those obtained at room temperature.

It is well visible from the table a strong difference between the critical stress $\tau_{c}$ measured at room temperature (67 MPa) and that obtained in the present work (153 MPa).

\subsection{Computing the radius of the control volume}

According to [62-64], the radius of the control volume for a bar with a circumferential crack subjected to torsion can be obtained through the following expression:

$$
R_{C}=\left(\frac{e_{3}}{1+v}\right)\left(\frac{K_{l I L c}}{\tau_{c}}\right)^{2}
$$

where $K_{\text {IIIc }}$ is the mode III critical stress intensity factor obtained through Eq. ( 3 ) and, for the crack case, $e_{3}=0.4138$, as shown in [62-64].

By considering the average values of the critical stress $\tau_{c}$ measured from the semicircular specimens as described above and the average value of the critical stress intensity factor $K_{\text {IIIc }}$ (see Tables 6 and 7 ), the control volume radius becomes:

$$
R_{C}=\left(\frac{0.4138}{1+0.4}\right)\left(\frac{6.02 \times 1000^{0.5}}{153.1}\right)^{2}=0.46 \mathrm{~mm}
$$

Table 6

Critical mode III stress intensity factors at room and low temperature.

\begin{tabular}{llll}
\hline Specimens & $d(\mathrm{~mm})$ & \multicolumn{2}{l}{ Mode Ill stress intensity factor } \\
\cline { 2 - 4 } & & Room temp. (MPa m $\left.{ }^{1 / 2}\right)$ & 5.61 \\
1 & 3 & 3.38 & 5.33 \\
2 & 3 & 3.20 & 5.96 \\
3 & 3 & 3.48 & 6.33 \\
4 & 3 & - & 6.38 \\
5 & 2 & - & 6.49 \\
6 & 2 & 3.35 & 6.02 \\
\hline
\end{tabular}

\begin{tabular}{|c|c|c|}
\hline Mechanical property & $-60^{\circ} \mathrm{C}$ & $20^{\circ} \mathrm{C}$ \\
\hline Shear elastic modulus (MPa) & 1800 & 1280 \\
\hline Elastic modulus (MPa) & 5050 & 3600 \\
\hline Poisson's ratio & 0.4 & 0.4 \\
\hline Tensile strength (MPa) & 128.4 & 74.0 \\
\hline Torsional strength (MPa) & 153.1 & 67.0 \\
\hline Fracture toughness $K_{\mathrm{IC}}\left(\mathrm{MPa} \mathrm{m}^{1 / 2}\right)$ & 1.7 & 1.0 \\
\hline Critical $K_{\text {III }}\left(\mathrm{MPa} \mathrm{m}^{1 / 2}\right)$ & 6.02 & 3.35 \\
\hline
\end{tabular}

Table 7

Mechanical properties of PMMA at different temperatures. 


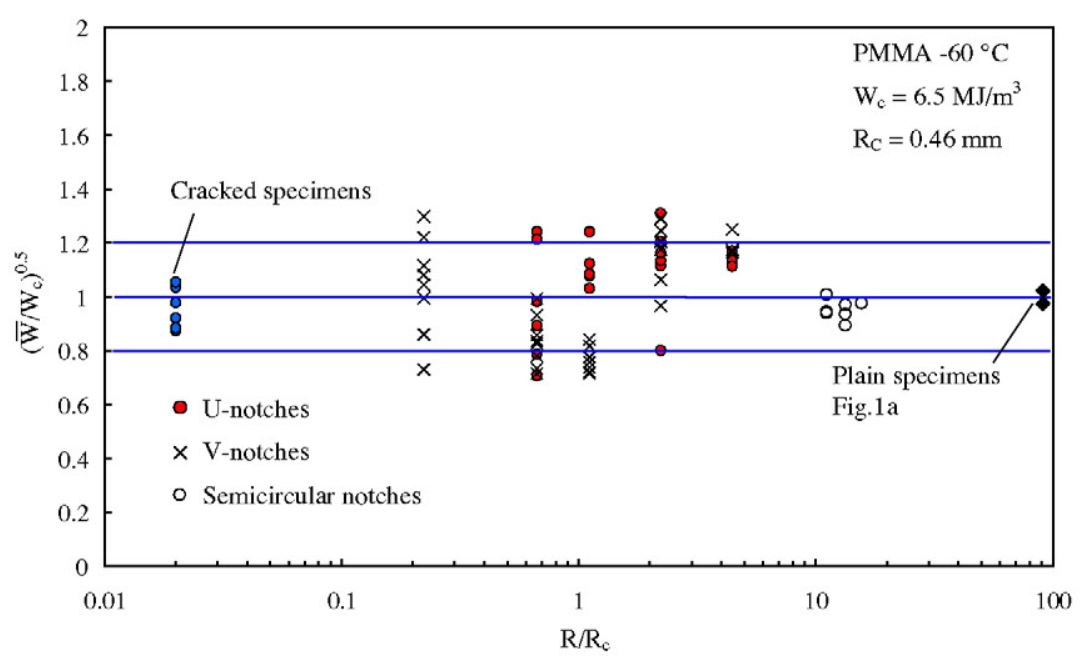

Fig. 12. Synthesis based on the apparent SED; $R_{C}=0.46 \mathrm{~mm}$. Scatter band taken from [61].

Contrary to Ref. [61], where the presence of large scale yielding did not allow to establish a priori the value of the radius, in the present contribution the radius has been determined from measurements with smooth notched specimens and cracked specimens $[19,21]$. Note that the obtained value for the critical radius is very high in comparison with that found for the same material under tension loads: $R_{C}=0.1 \mathrm{~mm}$ at room temperature [21], reduced to $R_{C}=0.035 \mathrm{~mm}$ at $-60{ }^{\circ} \mathrm{C}$ [37-39]. It is just a bit lower, $R_{C}=0.46 \mathrm{~mm}$, than the reference value $R_{\mathrm{ref}}=0.5 \mathrm{~mm}$ proposed in [61] for the final synthesis in terms of SED.

\subsection{Computing the critical energy}

The critical energy value can be obtained from the maximum shear strength $\tau_{c}$ by using the following expression:

$$
W_{c}=\frac{\tau_{c}^{2}}{2 G}
$$

where $G$ is the shear modulus.

By substituting the critical stress $\tau_{c}$ and the $G$ modulus measured from the plain specimens as explained above, we find $W_{c}=6.5 \mathrm{MJ} / \mathrm{m}^{3}$.

\subsection{Computing the average strain energy density}

Having obtained the $R_{C}$ value in Section 3.1, the mean value of the strain energy density over the control volume can be easily evaluated using the mode III notch stress intensity factor (sharp notches), the theoretical stress concentration factor (blunt notches) or directly from finite element models. As discussed in $[66,67]$ the SED can be accurately evaluated by using a coarse mesh.

For a blunt V-notch under mode III loading, the volume is axi-symmetric while the cross section is the crescent shape which cross section is the crescent shape shown in Fig. 11, where $R_{C}$ is the depth measured along the notch bisector line. The outer radius of the crescent shape is equal to $R_{C}+r_{0}$, being $r_{0}$ the distance between the notch tip and the origin of the local coordinate system (Fig. 10), $r_{0}=R(\pi-2 \alpha) /(2 \pi-2 \alpha)$, which depends on the V-notch opening angle $2 \alpha$ and the notch root radius $R$.

With the aim to evaluate the SED for the 22 considered geometries, finite element simulations have been performed by using Ansys 11 and assuming a linear elastic behaviour for the material (with the mechanical properties shown in Table 7 for the PMMA at $-60^{\circ} \mathrm{C}$ ). Although some non-linear effects which yet characterise (also at low temperature) the torque versus angle ( $25 \mathrm{~mm}$ gauge length) curves this assumption seems to be realistic. By comparing Figs. 9 and 10 it is evident that at low temperature the behaviour is more brittle in terms of failure angles and the notch sensitivity of the material is strongly increased with respect to the tests carried out at room temperature [61]. The detailed values of SED are listed in the last column of Tables 2-5. 


\subsection{Analysis of results}

Fig. 12 summarises all the data from $-60^{\circ} \mathrm{C}$ tests.

The square root of the normalised value of the average strain energy density is plotted versus the notch tip radius normalised by the control radius $R_{C}$. The scatter is increased with respect to the range 0.8-1.2 found at room temperature [61]. On the other hand, the dispersion of the data with respect to the reference value $W_{c}$ seems to be well-balanced and the relative deviation is comparable to that found in previous syntheses for PMMA tested at low temperature under mixed mode loading (I+ II) [37-39].

Fig. 13a-c shows a comparison between the assessed values of torques based on the SED and the experimental values from U-notches $(d=2 \mathrm{~mm}), V$-notches $(d=2 \mathrm{~mm})$ and semicircular notches tested at low temperature. The trend for the assessed torque is satisfactory.
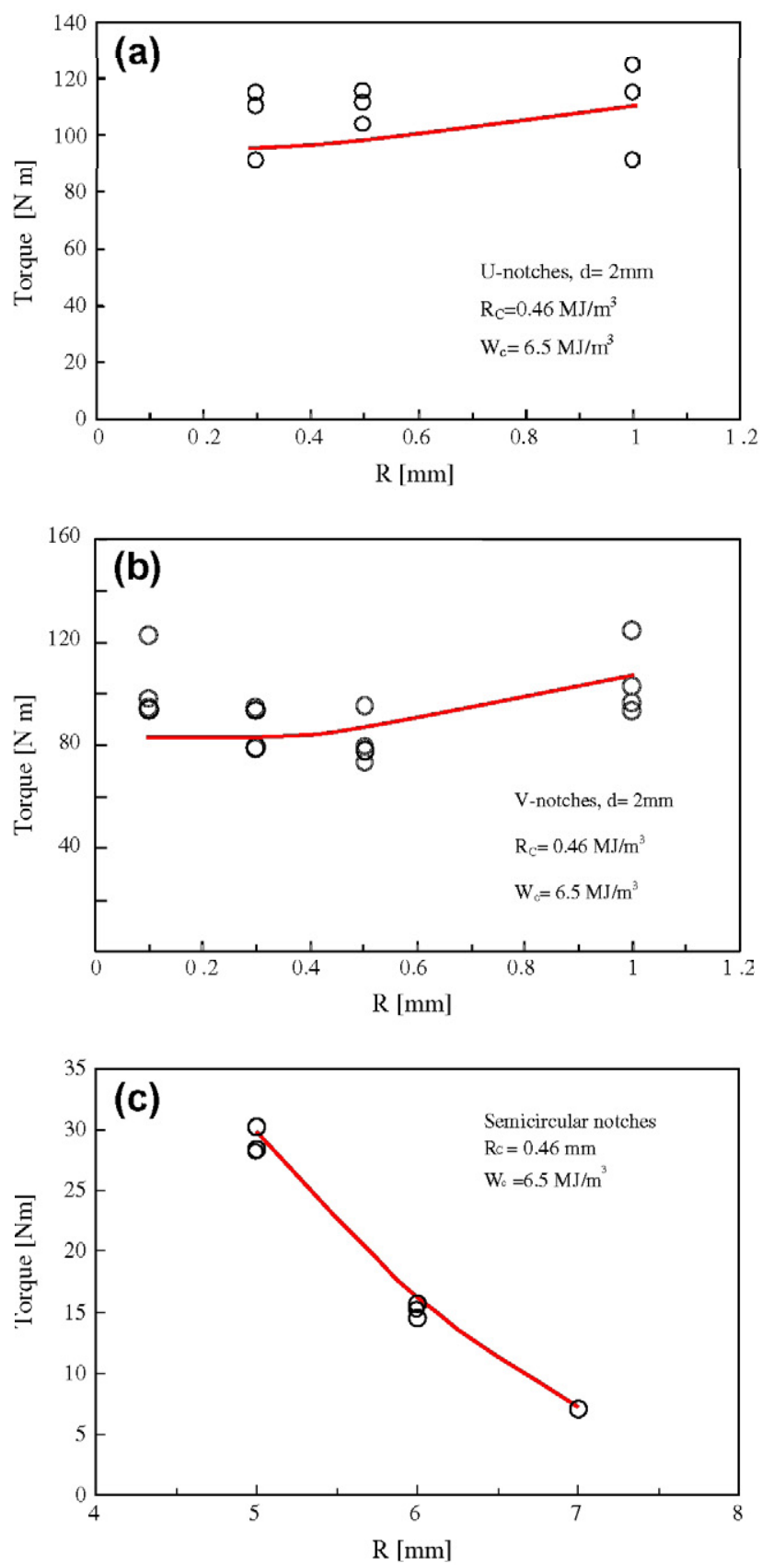

Fig. 13. Comparison between experimental and theoretical results based on the mean SED for U-notches (a), V-notches (b) and semicircular specimens (c). 


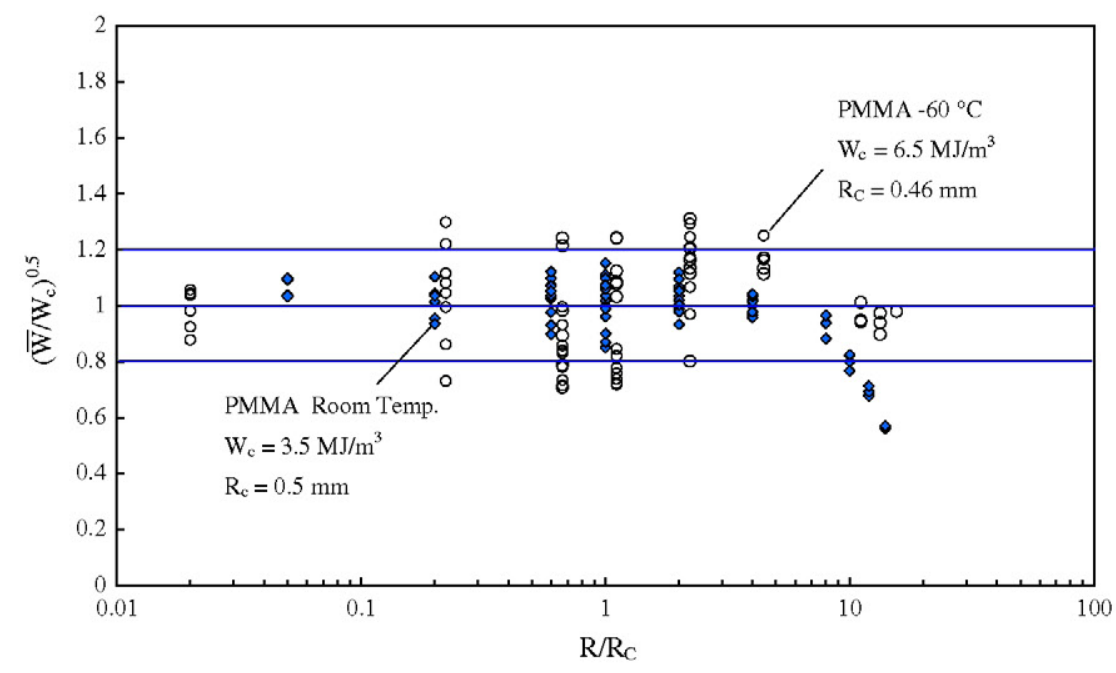

Fig. 14. Comparison between results at room temperature and at $-60^{\circ} \mathrm{C}$ in terms of SED.

A final synthesis comparing the data obtained in Ref. [61] from room temperature tests and those obtained in the present work from low temperature tests is shown in Fig. 14. For all data obtained at room temperature the SED has been evaluated over a control volume having a reference radius equal to $0.5 \mathrm{~mm}$, as explained in [61]. In contrast to the room temperature tests, where the results for semicircular notches with $R$ greater than $5 \mathrm{~mm}$ lied outside the scatterband, at low temperature all these data fall inside it. As expected, the reference value of the critical SED is very different at room temperature when compared with that obtained at $-60^{\circ} \mathrm{C}\left(3.5 \mathrm{MJ} / \mathrm{m}^{3}\right.$ against $\left.6.5 \mathrm{MJ} / \mathrm{m}^{3}\right)$.

On the basis of the results obtained in the present work, it seems that the strong non-linear effects observed at room temperature, have been reduced (although not at all removed) with the new tests at low temperature on the same material. The specimens tested at $-60^{\circ} \mathrm{C}$ have shown a more brittle behaviour. However, some evident non-linear effects are present also at $-60^{\circ} \mathrm{C}$ but, contrary to room temperature tests, in this case the failure is sensitive to the stress concentration effects and then to the shape of the notch, in particular to the notch tip radius.

Future efforts have to be devoted to consider the real material behaviour for improving the fracture assessment in presence of non-linearities, at least for small scale yielding (see Refs. [68-73]).

\section{Conclusions}

This paper gives an account of about 70 new fracture tests from notched specimens (with notches of different depth and radii), loaded under torsion at $-60^{\circ} \mathrm{C}$. In all tests, maximum loads and failure angles were measured as a function of notch root radius and specimens geometrical configuration. Repeatability of measurements was rather good considering the unavoidable small differences in machining notch root radii.

Although the temperature decrease makes the specimens behaviour considerably more brittle in terms of failure angles with respect to the tests performed at room temperature, the torque versus angle curves display a clear non-linear shape from their beginning, independently of the type of notch geometry. However the results show a good sensitiveness to the notch effect in particular to the notch radius and depth. The data are less influenced by the notch opening angle.

A final synthesis of the present data in terms of strain energy density is carried outin the paper, summarising previous results at room temperature and the new results at $-60^{\circ} \mathrm{C}$.

At room temperature, despite the largely inelastic behaviour of the PMMA, the results obtained provided a good prediction of the maximum torques but only up to a limit value of the notch root radius (about $5 \mathrm{~mm}$ ). At low temperatures this restriction is removed and all results lay inside the scatter band. Despite the slight non-linear behaviour, failure is basically governed by the stress concentration effects and the SED criterion is again able to provide a good prediction of the maximum torque for all specimens.

At $-60^{\circ} \mathrm{C}$, the radius of the volume has been determined a priori by using as input parameters the critical shear stress from smooth notched specimens and the critical stress intensity factor from cracked specimens as well as the Poisson's ratio. The synthesis allowed us to summarise all the data independently of the notch root radius and notch depth in a single scatter band slightly enlarged with respect to that reported in [61]. The scatterband includes the data from cracked specimens as well as the data from semicircular and unnotched specimens. 


\section{Acknowledgements}

This work was supported by the Italian Research Program CPDA100715 entitled "Static and fatigue behaviour of structural notched components subjected to tension and torsion under small or large scale yielding" and by the PRIN project 2009Z55NWC_001.

Prof. M. Elices and Prof. D.A. Cendón would also like to express their gratitude to the Spanish Ministerio de Economía y Competitividad for financial support through Project BIA2011-24445.

\section{References}

[1] Papadopoulos GA, Paniridis PI. Crack initiation from blunt notches under biaxial loading. Engng Fract Mech 1988;31:65-78.

[2] Leguillon D. Strength or toughness? A criterion for crack onset at a notch. Eur J Mech Phys A/Solids 2002;21:61-72.

[3] Leguillon D, Yosibash Z. Crack onset at a V-notch. Influence of the notch tip radius. Int J Fract 2003;122:1-21.

[4] Yosibash Z, Priel E, Leguillon D. A failure criterion for brittle elastic materials under mixed-mode loading. Int J Fract 2006:141:291-312.

[5] Leguillon D, Quesada D, Putot C, Martin E. Prediction of crack initiation at blunt notches and cavities-size effects. Engng Fract Mech 2007;74:2420-36

[6] Seweryn A, Poskrobko S, Mróz Z. Brittle fracture in plane elements with sharp notches under mixed-mode loading. J Engng Mech 1997;123:535-43.

[7] Seweryn A. Brittle fracture criterion for structures with sharp notches. Engng Fract Mech 1994;47:673-81.

[8] Nui LS, Chehimi C, Pluvinage G. Stress field near a large blunted tip V-Notch and application of the concept of the critical notch stress intensity factor (NSIF) to the fracture toughness of very brittle materials. Engng Fract Mech 1994;49:325-35

[9] Dunn ML, Suwito W, Cunningham S. Fracture initiation at sharp notches: correlation using critical stress intensities. Int J Solids Struct 1997;34:3873-83.

[10] Strandberg M. Fracture at V-notches with contained plasticity. Engng Fract Mech 2002;69:403-15.

[11] Lazzarin P, Filippi S. A generalised stress intensity factor to be applied to rounded V-shaped notches. Int I Solids Struct 2006:43:2461-78.

[12] Gomez FJ, Elices M, Berto F, Lazzarin P. A generalised notch stress intensity factor for U-notched components loaded under mixed mode. Engng Fract Mech 2008;75:4819-33.

[13] Berto F, Lazzarin P, Radaj D. Fictitious notch rounding concept applied to sharp V-notches: evaluation of the microstructural support factor for different failure hypotheses Part II: microstructural support analysis. Engng Fract Mech 2009;76:1151-75.

[14] Berto F, Lazzarin P, Radaj D. Fictitious notch rounding concept applied to V-notches with root holes subjected to in-plane shear loading. Engng Fract Mech 2012;79:281-94.

[15] Sih GC, Ho JW. Sharp notch fracture strength characterized by critical energy density. Theor Appl Fract Mech 1991;16:179-214.

[16] Ayatollahi MR, Sedighiani K. Mode I fracture initiation in limestone by strain energy density criterion. Theor Appl Fract Mech 2012;57:14-8.

[17] Glinka G. Energy density approach to calculation of inelastic strain-stress near notches and cracks. Engng Fract Mech 1985;22:485-508.

[18] Ellyin F, Kujawski D. Generalization of notch analysis and its extension to cyclic loading. Engng Fract Mech 1989;32:819-26.

[19] Lazzarin P, Zambardi R. A finite-volume-energy based approach to predict the static and fatigue behaviour of components with sharp V-shaped notches. Int J Fract 2001;112:275-98

[20] Yosibash Z, Bussiba A, Gilad I. Failure criteria for brittle elastic materials. Int ] Fract 2004:125:307-33.

[21] Lazzarin P, Berto F. Some expressions for the strain energy in a finite volume surrounding the root of blunt V-notches. Int J Fract 2005; 135:161-85.

[22] Livieri P. Use of J-integral to predict static failures in sharp V-notches and rounded U-notches. Engng Fract Mech 2008;75:1779-93.

[23] Berto F, Lazzarin P. Matvienko YG.J-integral evaluation for U- and V-blunt notches under mode I loading and materials obeying a power hardening law. Int J Fract 2007;146:33-51.

[24] Bazant ZP, Planas J. Fracture and size effect in concrete and other quasi-brittle materials. CRC Press; 1998 [chapter 7].

[25] Elices M, Guinea GV, Gómez FJ, Planas J. The cohesive zone model: advantages, limitations and challenges. Engng Fract Mech 2002;69:137-63.

[26] Gômez FJ, Elices M. Fracture of components with V-shaped notches. Engng Fract Mech 2003;70:1913-27.

[27] Gómez FJ, Elices M. A fracture criterion for blunted V-notched samples. Int J Fract 2004;127:239-64.

[28] Gómez FJ, Elices M, Planas J. The cohesive crack concept: application to PMMA at $-60^{\circ} \mathrm{C}$. Engng Fract Mech 2005;72:1268-85.

[29] Gómez F], Guinea GV, Elices M. Failure criteria for linear elastic materials with U-notches. Int J Fract 2006;141:99-113.

[30] Atzori B, Lazzarin P, Meneghetti G. Fracture mechanics and notch sensitivity. Fatigue Fract Engng Mater Struct 2003;26:257-67.

[31] Theocaris PS. A higher order approximation for the T-criterion of fracture in biaxial fields. Engng Fract Mech 1984;19:975-91.

[32] Ayatollahi MR, Aliha MRM. Analysis of a new specimen for mixed mode fracture tests on brittle materials. Engng Fract Mech 2009;76:1563-73.

[33] Ayatollahi MR, Torabi AR. Determination of mode II fracture toughness for U-shaped notches using Brazilian disc specimen. Int J Solids Struct 2010;47:454-65.

[34] Ayatollahi MR, Torabi AR. Investigation of mixed mode brittle fracture in rounded-tip V-notched components. Engng Fract Mech 2010;77:3087-104.

[35] Ayatollahi MR, Aliha MRM, Saghafi H. An improved semi-circular bend specimen for investigating mixed mode brittle fracture. Engng Fract Mech 2011;78:110-23.

[36] Ayatollahi MR, Shadlou S, Shokrieh MM. Mixed mode brittle fracture in epoxy/multi-walled carbon nanotube nanocomposites. Engng Fract Mech 2011;78:2620-32.

[37] Gómez FJ, Elices M, Berto F, Lazzarin P. Local strain energy to assess the static failure of U-notches in plates under mixed mode loading. Int J Fract 2007;145:29-45

[38] Berto F, Lazzarin P, Gomez F], Elices M. Fracture assessment of U-notches under mixed mode loading: two procedures based on the 'equivalent local mode I' concept. Int J Fract 2007;148:415-33.

[39] Gómez FJ, Elices M, Berto F, Lazzarin P. Fracture of V-notched specimens under mixed mode (I + II) loading in brittle materials. Int J Fract $2009 ; 159: 121-35$

[40] Lazzarin P, Berto F, Elices M, Gómez J. Brittle failures from U- and V-notches in mode I and mixed, I+ Il, mode. A synthesis based on the strain energy density averaged on finite size volumes. Fatigue Fract Engng Mater Struct 2009;32:671-84.

[41] Gomez FJ, Elices M, Berto F, Lazzarin P. Fracture of U-notched specimens under mixed mode: experimental results and numerical predictions. Engng Fract Mech 2009;76:236-49.

[42] Berto F, Lazzarin P. A review of the volume-based strain energy density approach applied to V-notches and welded structures. Theor Appl Fract Mech 2009:52:183-94.

[43] Wang NM. Twisting of an elastic plate containing a crack. Int J Fract 1970;6(4):367-78.

[44] Raju KR. Effect of depth of side grooves in double torsion specimens on plane strain fracture toughness. Int J Fract 1981;17:R189-90.

[45] Cheung YK, Wang YH. The torsion of a bar with arbitrary section containing two edge cracks. Int J Fract 1991;47:307-17.

[46] Davenport JCW, Smith DJ. A study of superimposed fracture modes I, Il and III on PMMA. Fatigue Fract Engng Mater Struct 1993;6:1125-33.

[47] Bisen Lin, Mear ME, Ravi-Chandar K. Criterion for initiation of cracks under mixed-mode I + III loading. Int J Fract 2010;165:175-88.

[48] Leblond JB, Karma A, Lazarus V. Theoretical analysis of crack front instability in mode I + III. J Mech Phys Solids 2011;59:1872-87.

[49] Zheng X, Zhao K, Wang H. Failure criterion with given survivability for ceramic notched elements under combined tension/torsion. Mater Sci Engng A $2003 ; 357: 196-202$ 
[50] Zheng XL, Zhao K, Yan JH. Fracture and strength of notched elements of brittle material under torsion. Mater Sci Tech 2005;21:539-45.

[51] Berto F, Lazzarin P, Ayatollahi MR. Brittle fracture of sharp and blunt V-notches in isostatic graphite under torsion loading. Carbon 2012;50:1942-52.

[52] Tanaka K. Engineering formulae for fatigue strength reduction due to crack-like notches. Int J Fract 1983;22:R39-46.

[53] Qian J, Hasebe N. Property of eigenvalues and eigenfunctions for an interface V-notch in antiplane elasticity. Engng Fract Mech 1997;56:729-34.

[54] Lazzarin P, Zappalorto M, Yates JR. Analytical study of stress distributions due to semi-elliptic notches in shafts under torsion loading. Int J Engng Sci 2007;45:308-28.

[55] Zappalorto M, Lazzarin P, Yates JR. Elastic stress distributions resulting from hyperbolic and parabolic notches in round shafts under torsion and uniform antiplane shear loadings. Int J Solids Struct 2008;45:4879-901.

[56] Zappalorto M, Lazzarin P, Berto F. Elastic notch stress intensity factors for sharply V-notched rounded bars under torsion. Engng Fract Mech $2009 ; 76: 439-53$.

[57] Zappalorto M, Lazzarin P, Filippi S. Stress field equations for U and blunt V-shaped notches in axisymmetric shafts under torsion. Int J Fract 2010;164:253-69.

[58] Atzori B, Zappalorto M, Berto F. A theoretical treatise for notch and defect sensitivity under torsion. Mech Res Commun 2010;37:173-6.

[59] Zappalorto M, Berto F, Lazzarin P. Practical expressions for the notch stress concentration factors of round bars under torsion. Int J Fatigue 2011;33:382-95.

[60] Susmel L, Taylor D. The theory of critical distances to predict static strength of notched brittle components subjected to mixed-mode loading. Engng Fract Mech 2008;75:534-50.

[61] Berto F, Lazzarin P, Elices M, Zappalorto M. Fracture behaviour of notched round bars made of PMMA subjected to torsion at room temperature. Engng Fract Mech 2012;90:143-60.

[62] Lazzarin P, Livieri P, Berto F, Zappalorto M. Local strain energy density and fatigue strength of welded joints under uniaxial and multiaxial loading. Engng Fract Mech 2008;75:1875-89.

[63] Berto F, Lazzarin P, Yates JR. Multiaxial fatigue of V-notched steel specimens: a non-conventional application of the local energy method. Fatigue Fract Engng Mater Struct 2011;34:921-43.

[64] Berto F, Lazzarin P. Fatigue strength of structural components under multi-axial loading in terms of local energy density averaged on a control volume. Int J Fatigue 2011;33:1055-65.

[65] Coulomb M. Recherches théoriques et expérimentales sur la force de torsion et sur l'élasticité des fils de metal. Histoire de l'Académie Royale des Sciences; 1784:229-69.

[66] Lazzarin P, Berto F, Gómez FJ, Zappalorto M. Some advantages derived from the use of the strain energy density over a control volume in fatigue strength assessments of welded joints. Int J Fatigue 2008;30:1345-57.

[67] Lazzarin P, Berto F, Zappalorto M. Rapid calculations of notch stress intensity factors based on averaged strain energy density from coarse meshes: theoretical bases and applications. Int J Fatigue 2010;32:1559-67.

[68] Glinka G. Energy density approach to calculation of inelastic strain-stress near notches and cracks. Engng Fract Mech 1985;22:485-508.

[69] Glinka G. Calculation of inelastic notch-tip strain-stress histories under cyclic loading. Engng Fract Mech 1985;22:839-54.

[70] Guo W, Wang CH, Rose LRF. Elastoplastic analysis of notch-tip fields in strain hardening materials. Report DSTO-RR-0137 1998, DSTO Aeronautical and Maritime Research Laboratory, Melbourne, Vic., Australia.

[71] Lazzarin P, Zambardi R. the equivalent strain energy density approach reformulated and applied to sharp V-shaped notches under localised and generalised plasticity. Fatigue Fract Engng Mater Struct 2002;25:917-28.

[72] Torabi AR. On the use of the equivalent material concept to predict tensile load-bearing capacity of ductile steel bolts containing V-shaped threads. Engng Fract Mech 2013;97:136-47

[73] Torabi AR. Estimation of tensile load-bearing capacity of ductile metallic materials weakened by a V-notch: the equivalent material concept. Mater Sci Eng A 2012;536:249-55. 